\title{
To Investigate the Factors on life Satisfaction (of Adolescents in Ahwaz)
}

\section{Reza Esmaeili1, Samira Heidari², Reza Shahmorady², Ezat Allah Safaee $^{2}$}

\author{
${ }^{1} \mathrm{PhD}$ in Sociology and Department of Cultural Management and Planning, Islamic Azad University, Isfahan \\ ${ }^{2} \mathrm{PhD}$ sociology student at Azad University Dehaghan
}

\begin{abstract}
This study aimed to investigate the factors of the life satisfaction of adolescents from Ahvaz to discuss the issue and determine the theoretical framework of relevant sociological perspectives and assumptions were derived from it. This research is a questionnaire survey and data collection, statistical population in this study, all adolescents Ahwaz city, the sample size was determined based on a sample of 384 people. In terms of when this study was conducted in 1393. The results show that all independent variables except the variable sense of fairness significant relationship with the dependent variable they do.
\end{abstract}

Keywords: family life satisfaction, power structure, satisfy the need of feeling, a sense of security

\section{Introduction and question}

Taking from the past, a prosperous and happy life free from very diverse definitions are applied, one of the human mind needs and continuous efforts have been made to achieve it. Utmost cultural and human civilization, in order to create the context, capabilities and resources necessary to improve the quality and quantity of life and its meaning was.

The concept of life satisfaction, although it follows a more general concept of quality of life and economic measures were introduced in response to the review in an independent area and it quickly became a major in the social sciences. Bradbvrn Norman and David Kaplvvytz opinion of the National Center for America of the first ones to feel the satisfaction of their assessment. They understand the life satisfaction of social development policy and planning at national governments had pointed out. (Hezarjaribi, 11: 1388) to provide a comprehensive definition of the concept of life satisfaction is not so easy, because each person is different understanding of the concept there. Diener (1999), life satisfaction as a subjective evaluation of the overall quality of their life or some aspect of his life is defined. Habnr (2004), for life satisfaction there is both subjective and objective. Life satisfaction in terms of control over the externally focused objective and subjective view on the subjective judgment of life satisfaction (satisfaction with friends, family and living environment) refers. Despite numerous definitions that are provided for the concept of life satisfaction, we can find common ground among the various aspects of this important category of human beings, you may be eligible for this feature is defined by Campbell of life satisfaction, in his opinion on the experience of satisfaction recognition implies that the "perceived gap between ambition and achievement in life(ie, wish fulfillment) is defined. in other words reflect the feelings of life satisfaction and overall view of people of the world in which they live.

The study of factors influencing satisfaction of family life into consideration their teens.this negative potential from potential to actual and not potential. Accordingly, the low satisfaction index of family life as a pathological signal and indicates if the capacity of families to be taken. Although the statistics and detailed information about the family life satisfaction does not exist in Iran, but to look at the statistics, family problems, divorce, rape, incest, running away from home, mental health issues, or at least teens to some extent can be correlated outcomes the disapproval of family life within the community can be touched. Satisfaction element, a basic element of the order, is community consensus. It should be noted that there is continuing dissatisfaction in people's lives is problematic for the social system but is rooted in objective conditions. We cannot ignore the fact that the main components in positive and negative assessment of each individual, subjective analysis and evaluation of their condition and society to adapt

This article is published under the terms of the Creative Commons Attribution License 4.0 Author(s) retain the copyright of this article. Publication rights with Alkhaer Publications.

Published at: http://www.ijsciences.com/pub/issue/2016-04/

DOI: 10.18483/ijSci.978; Online ISSN: 2305-3925; Print ISSN: 2410-4477 
to others. The main problem in this study, satisfaction with family life and is its expression.

\section{The necessity and priority research}

The role and influence of family social science scholars have debated the future of youth development, family social symbol. Such as a mirror of society in itself and a reflection of social disorder. No society can never be well unless the families have healthy and satisfaction. (Sarookhani, 136: 1392)

One of the important areas of study was in the sociology of the family, interaction among family members. Although there is a tendency to cause the family and only one strain of relations within the family are concerned, but it should be noted family is always the paradise of the family ties have domination and oppression be a. William Jay. Deep in his book the family writes: "Even the most fortunate families can also be considered as a system of power. Because most of the time, each member trying to force others to do or stop doing working against the wishes of others.

Based on the results of research conducted in the field of social pathologies can be said that in recent years $80 \%$ of girls belonging to poor families escape and factors such as divorce, addiction, imprisonment, death and marriage Mjddvaldyn in escape girls played a role.

In relation to parental behavior in almost all cases Girls strict and harsh punishments were mentioned as one of the causes of escape. Among those who had attempted suicide were up 3/12 to children that their motivation is to get rid of adverse conditions the family. (Hosseini, 122: 1383) can therefore be consequences, or at least correlates touched dissatisfaction with family life within the community.So long as young people feel satisfied, always serving the city and the society more attention to them.quotes Madandar, 1388).

In our country in recent years, the issue of life satisfaction survey conducted recently in some of them the satisfaction of people's lives have also been considered. But clearly the contribution of independent studies to examine the personal satisfaction of family life was small. In this article, attempts to influence the power structure in the family and variables to satisfy needs, a sense of freedom, security and justice, family life satisfaction are assessed.

\section{Theoretical}

Hierarchy of needs theory:

Maslow's hierarchy of human needs to be placed in five categories: 1.nyaz Psychological obvious need of food, water and air, and sex that is essential for survival Arzayshan, hence physical needs is the strongest needs.

2.nyaz security: after the physical needs, safety needs are human motivation, the needs include security, stability, support, learning, freedom from fear and anxiety.

3.nyaz belonging and love and dependence: When you've achieved a certain level of feelings of safety and security, we noticed satisfy the needs of belonging and love.

4.nyaz respect: if enough of a sense of love and belonging benefit, then we need to feel respected Dasht.mazlv need to respect the difference between the two is laid.

5.nyaz to self-realization: If $\mathrm{Hmh} \neg \mathrm{Y}$ meet these requirements, then the greatest need, namely the need to fulfill the MyᄀVrym. (Hezarjaribi, 12: 1388)

The central idea of this theory is that human needs are hierarchical in terms of growth and dominate the behavior, require lower, the strongest impulses are dominant, while the weakest motivation is the need for self-actualization. (Mac Klnd, 514: 1385, quoting Alderman, 1390) with the consent of organic communication requirements. Despite not require or bring your design, followed by human movement, efforts not do it, the concept of consent can not be raised. (Mohsen Saleh, 1: 1382)

\section{Exchange theory:}

George Casper Homans theory on the idea that psychological rewards individuals for psychological costs must be paid. (Valdman, 98: 1972), one the one hand, in search of maximum profit or the highest rewards like other hand, is seeking to reduce costs to a minimum, Homans concludes that the existing behavior is the most precise way. (recourse, 1373: 39). in the theory of exchange, a person in the family for the task he was doing, waiting is. The agreement that the community of respected, but if the family of the interests of the person refuses, conflict arises between the interests of the members' interests and consequently leads to dissatisfaction. People assume that rewards those who participates in interaction with each other, they should be proportionate to costs, the principle of distributive justice is of the opinion that in 1967, it raised Homans, when this principle was not respected in the case of the loss of innocent justice is more people, the more likely he is more anger and dissatisfaction (thousand acres, 12: 1388)

Wish theory - compliance:

Ingelhart, in 1990, its theoretical framework established by two theories: scarcity and socialization hypothesis. Conditions for economic recovery and 
relief after World War led to a historic change in which the need to respect, granting more rights to individuals and communities in decision-making related to labor relation to others, subjective and aesthetic satisfaction is more important than trying in order to obtain food and security. But socialization hypothesis states that individual values largely reflect the circumstances in which he prevailed during the years before puberty (Ingelhart, 1378: 61)

He believes that growth post-industrial values, loss of respect for authority and the growing emphasis on participation and self-expression to bring. According to him, post-material values-oriented emphasis on freedom of expression involves personal and political, protest activities of youth, freedom, tolerance of others and focusing on mental well-being in life satisfaction is reflected. (Ingelhart and Welzel, 1389: 21).(Welzel et al, 1382: 26) in Ingelhart life satisfaction reflects the balance between the wishes and the status quo, when the status of the person in the household with high hopes and expectations adapted to the individual loses a sense of satisfaction, when the person Find this match will be in trouble dissatisfaction and unhappiness. (sower, 69: 1386)

\section{Metropolis and Mental Life theory:}

Metropolis that affect the structure of urban life are: "1. nerve stimulation reflect the changing external stimuli 2. the need to rely on reason and rationalism, precision and accuracy of object 3. human significance because of the economy and monetary rationality on the part of urban life and the special interests and conflicts precautionary 4. 5. loneliness, isolation and self Bygangy6- value of art and other aspects of human culture of poverty. "(founder of the Poor, 1387: 122).

Simmel can be two views about life satisfaction judgment, the first since the rationality of urban life and his words of wisdom and a sense of place and relationships metropolis is the place. This behavior can be calculated reasonably and valued individual life satisfaction and higher satisfaction from the perspective of family life experience. satisfaction with life. (autonomous and theoretical, 1389: 116).

\section{Anomie theory:}

Emile Durkheim in terms of family life satisfaction function of the type, severity, and how social. Social relationship of the two to the satisfaction of life is affected. On the one hand the need to provide emotional, cognitive, financial, even individual, his satisfaction increases and the other by blocking tendencies of the endless and insatiable ambitions can be used to prevent Durkheim, well organized societies, social regulations on demographic trends, build a series of limitations, set binding social where are disruptive influence on attitudes towards personal supervision of the society, it will lose its effectiveness and will leave people had their own was. In this situation, wishes another person with common norms are not regulated and therefore such people without moral guidance, and each one only his personal goal to pursue. With the disintegration of the norm (and thus loss of control wishes), anomie or a situation arises limitless ambitions, since it can satisfy the wishes of some naturally become saturated, resulting in a state of permanent dissatisfaction family members emerge. (RAFIPOUR, 1378: 18)

\section{The relative deprivation theory}

Ted Robert Gurr, the theory of relative deprivation is believed that if they create a barrier to the achievement of the goals and their aspirations: they have a biological relative deprivation and the natural outcome and all this, as a source of damage deprivation. Thus, relative deprivation result of differences between expectations and perceived value (desires) and potential value (that of) the natural products of the state of frustration and dissatisfaction in their creation and the need in people. (Ibid.,30)

\section{Theoretical Framework}

Since none of the theories are not comprehensive research on the issue, so a hybrid approach was used in order to link theory and practice from the theory of Maslow's hierarchy of needs, and the theory of exchange value difference Ingelhart has been used.

Table 1. Extract the variables theories of thinkers

\begin{tabular}{|l|l|}
\hline thinkers & Variable \\
\hline Maslow & meet the needs of \\
\hline Homans & sense of justice \\
\hline Ingelhart & family structure - the feeling of freedom \\
\hline
\end{tabular}




\section{History Research \\ A) internal studies}

-Mohseni (1379), as a result of his research, which was published in book form, the concept of pay satisfaction: satisfaction social researcher considers seven dimensions, including "satisfaction hometowns, family satisfaction, satisfaction individual health, satisfaction of feeding, housing satisfaction, satisfaction with financial situation, satisfaction of fortunes. " Full dissatisfaction with life equal to $6 / 7$ percent and the proportion of people quite content equal to $7 / 65$ percent. The ideas in the middle of them and said they are somewhat satisfied with their lives in 7/25 percent.

- Mohseni and Salehi (1382), in a study as social satisfaction in Iran achieved the following results: a) the consent of family life in different age groups, were high and close together. Among Youth 9/84\%, middle-aged $4 / 81 \%$ and seniors $7 / 81 \%$ of family life have been satisfied. The remaining percentage of each group, owned by individuals have been satisfied, somewhat dissatisfied. B) the amount of youthful discontent is lower and looks with age, the grievances of family life a little more.

-AZimy (1382), in their study to identify religiosity and life satisfaction and its components and its funds and the relationship between these two variables among students (1,200 students from high schools in Mashhad) country. The results show that there is a significant relationship between religiosity and life satisfaction.

-Hezar jaribi, Safari Shali (1388), in his research entitled "Study of life satisfaction and sense of security in its place" to study and evaluate the role of life satisfaction and life satisfaction among young people feel safe on Tehran pay. Results of the research show that the variables have the greatest influence on life satisfaction had a sense of security, a sense of security dimensions of deprivation were other variables, trust in managers' efficiency, satisfy needs, socio-economic, social trust their effect on life satisfaction.

- Golchin, Zardmooy (1389), in a study as explained Tehran adolescents family life satisfaction in the fulfillment of family pattern in order to achieve this result: the degree of realization of order in the family, satisfy needs, feel unjust and freedom with consent there is a significant correlation of teenage life.

\section{B) Foreign Studies}

-Karolyn (1994), in his paper, entitled "Family life satisfaction" came to the conclusion that life satisfaction to the families of the highest correlation with parental support, flexibility, family, family reunion, family punishment (Solidarity negative) and parental arguments there.

- Pectin and Smith (2009), in his paper, entitled "life satisfaction" examines life satisfaction in both the
Netherlands and the United States is paid. The results show that for all of the dimensions (employment, social relationships and family income) and life satisfaction were significant differences between the Dutch and American respondents. This study shows that life satisfaction significantly with 4 next (jobs, health, social and family relationships and income) is associated. Coefficients to estimate the effect of satisfaction in life satisfaction show that the highest weight in the life satisfaction of social and family relationships, jobs, health and income are in second place then.

-Dych (2000), in a study entitled "student performance, work related and personal happiness social" Quality of life and satisfaction in the four hundred and sixty-seven thousand students and university graduates was conducted in Iceland. The study showed that seven major factor has a negative effect are two factors have a negative impact. Positive factors include: purpose in life, perceived opportunities, job satisfaction, health, friends, family and intimate relationships and negative factors, including a lack of power and emptiness.

\section{Research Hypothesis}

- It seems that satisfy the needs of family life satisfaction relationship is significant.

- It seems that the sense of justice and satisfaction with family has a significant relationship.

- It seems the feeling of freedom with family life satisfaction relationship is significant.

- Looks making power in the family and family life satisfaction has a significant relationship.

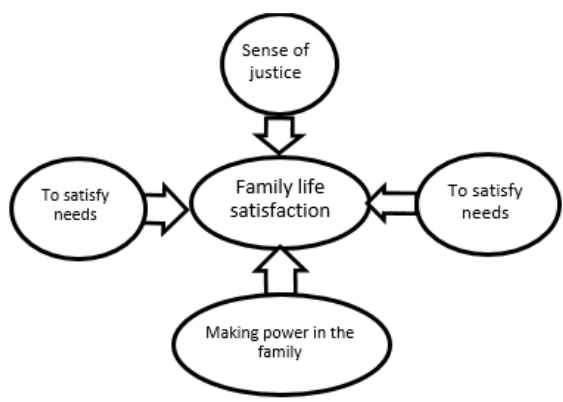

Figure 1.mdl Research

\section{Research Methodology}

Type of this research was applied. Method of research survey. Data gathered by questionnaire. As well as to prepare a conceptual framework and practical methods of documentation (library) that will be used to refer to the resources available. The unit of analysis is the study of the individual. Causes of the survey is to generalize the findings to maximize the power of statistical population in this study, all adolescents is the city of Ahwaz, Ahwaz city youth population according to the latest census, 860000 people. The sample size of 384 teenagers in Ahvaz, according to Cochran formula cluster sampling were 
selected and after the collect call response data using the software spss statistical descriptive and inferential statistical analysis is taken. In terms of when the survey was conducted in 1393.

\section{Dimension changing views \\ Independent variables}

- Satisfaction of needs: the need for a sense of loss or deprivation as a living organism that is going to realize its objectives, its lack sees things, loses. (Outdoor, 242: 1370, quoting Elite Zardmooy, 1390). In the context of the theory of Maslow (1375) was used. Maslow's hierarchy of human needs to be placed in five categories: physiological needs, the need for security (feel safe) Since the study was done at the household level feel safe only in three dimensions: physical, financial and intellectual evaluated needs for belonging and affection and affiliation, need to respect, cognitive demands (Hezarjaribi, 12: 1388)

- A sense of freedom: freedom with some positive aspect concerns the individual's assessment of the conditions and predictability of its dominance, as well as the individual access to opportunities to do different things. In other words, there are legitimate ways to achieve different individual wishes and needs. (Alizadeh, 83: 1386, quoting Elite Zardmooy, 1390)

- Sense of justice: individual sense of a situation in which all social values to be distributed equally, unless an unequal distribution of any or all of these values is in the interest of everyone. (Pajman, 46: 1386, quoting Elite Zardmooy, 2012)

- Making power in the family: construction means systematic patterns of social relationships between individuals or situations are defined and structured order making power in family decision-making patterns in the family. Our patterns are divided into the following four categories have:

1. Build a comprehensive dad axis of power in the decision making is driven father and his final say in most cases. In other words, the construction of the father highest decision-making power and decision making is mostly alone.

2. Build unilateral power mother-centric: a kind of power structure in the family in which the mother is more decision-making power.
3. Build strength relative symmetrical: in the decision making power almost equally divided between the parents. The main feature of the participation of both parents in the decision making power structure. The construction of the child may be able to express their opinions but ultimately the decision is with the parents. Construction of symmetric relative strength and rigidity have some degree of equality and partnership first two types of power away. The building is symmetrical because both parents are involved in decision-making and decision-making is partially why it is done with a focus on parents and the children are not included.

4. symmetrical all-round power structure means the sort of power structure in the family that power is distributed among nearly all family members and focus on one parent or both of them can not be seen in it. In fact, collaboration, consultation and participation in decision making important characteristic of this type of power in the family. In other words, the result of decisions in this type of collaboration, consultation and involvement of the public comments on matters relating to the family. (Sarookhani and Amirpanahy, 21: 1385)

Family life satisfaction: family life satisfaction the positive evaluation of his family life in its totality (products, Hubner and Lavvlyn, 151: 2000, quoting Elite Zardmooy, 1390)

In this study, to measure the dependent variable (family life satisfaction), the family and colleagues of seven items Hubner scale is used. Respondents were asked to rate their agreement or disagreement with the statements of the express. These items include:

1-of and live with my family under one roof enjoy 0.2-members of my family live happily together. 3 . I love my spare time I spent with my parents 4 . Our happiness in family entertainment together to do part of my family compared to other 0.5 -families who know, the better .6- We talk politely family together with my parents in the 0.7-altogether different backgrounds behave with justice and fairness.

Cronbach's alpha Satisfaction with Life Scale Hubner has done in his research, Cronbach's alpha values for the satisfaction of family life / 86. (Ibid., 153, quoting Elite Zardmooy, 1390), this study Cronbach's alpha values / 81. Has been achieved . 


\begin{tabular}{|l|l|l|l|l|}
\hline Variable & Type of test & $\begin{array}{l}\text { Significance } \\
\text { level }\end{array}$ & The test & test results \\
\hline $\begin{array}{l}\text { Symmetrical all-round power structure in the family and } \\
\text { family life satisfaction }\end{array}$ & R Pearson & $0 / 000$ & $0 / 321$ & Confirm \\
\hline $\begin{array}{l}\text { Making unilateral power driven father and family life } \\
\text { satisfaction }\end{array}$ & R Pearson & $0 / 000$ & $-0 / 274$ & Confirm \\
\hline $\begin{array}{l}\text { Making unilateral power-driven mother and family life } \\
\text { satisfaction }\end{array}$ & R Pearson & $0 / 000$ & $-0 / 195$ & Confirm \\
\hline $\begin{array}{l}\text { Symmetrical power structure relative and family life } \\
\text { satisfaction }\end{array}$ & R Pearson & $0 / 000$ & $0 / 265^{* *}$ & Confirm \\
\hline Sense of justice and satisfaction with family life & R Pearson & $0 / 652$ & $-0 / 023$ & Confirm \\
\hline A sense of freedom and satisfaction with family life & R Pearson & $0 / 000$ & $0 / 647$ & Confirm \\
\hline Feel satisfy the needs and satisfactions of family life & R Pearson & $0 / 000$ & $0 / 421$ & Confirm \\
\hline Gender and family life satisfaction & t & $0 / 001$ & $3 / 504$ & Confirm \\
\hline
\end{tabular}

\section{Research findings}

Describes the characteristics of the sample population

The average age of respondents is $34 / 22$ and teenagers aged between 15 and 18 years old respectively. Results based on gender variable showed that $56 / 51 \%$ of women and $44 / 48 \%$ of the sample were men.
Describes the features of the dependent variable: family life satisfaction

Table 2. Descriptive statistics of the dependent variable (family life satisfaction) .table indicates the average 62/27, 11/0 times the standard deviation and variance of the variable equal to $11 /$ is 0 . A minimum score of 14 and a maximum score is 35 .

Table 2: Descriptive statistics of family life satisfaction (the dependent variable)

\begin{tabular}{|c|c|}
\hline Descriptive statistics & Amount \\
\hline Average & $27 / 62$ \\
\hline Standard deviation & $0 / 11$ \\
\hline Variance & $21 / 03$ \\
\hline At least & 14 \\
\hline Maximum & 35 \\
\hline Number of Views & 384 \\
\hline
\end{tabular}

Test Hypotheses,

Table 3 shows the correlation of test results between independent variables and dependent variable (family life satisfaction) respectively. As the data show, due to the significant level reported a significant relationship between family structure and its dimensions (making unilateral power driven father, mother unilateral power structure centered) with the consent of family life and a significant negative relationship there is a sense of justice and satisfaction with family life, the significant relationship between the variables been observed. The sense of freedom and feel satisfy needs, and build strength and build strength in all aspects of family life satisfaction were positively correlated with satisfaction with family life also mean there is a significant difference in terms of gender. Significant level of correlation coefficients of each variable separately in Table 3 below.

Table 3: Correlation test between independent variables and the dependent variable

*. Correlation is significant at the 0.05 level (2tailed).

**. Correlation is significant at the 0.01 level (2tailed).

Determinants of satisfaction with family life: Regression Results

To determine the relative influence of independent variables on family life satisfaction of multivariate regression analysis was used. Of the independent variables (except for underlying variables) that were entered, only three variables, satisfaction of needs, 
making unilateral father, mother, mother-centric build a comprehensive significant that 58 per cent of updates to family life satisfaction these two variables account for the remaining variance explained by other variables that are not included in the research model.

The results show that the regression equation in increments of one standard deviation in the variable feel the satisfaction of needs, family life satisfaction $0 / 271$ standard deviation increase in size. Also in increments of one standard deviation centered power structure unilateral father, family life satisfaction as much as 0/248 standard deviation decreases as well as increases in variable manufacturing a standard unit in power of a mother-centered, family life satisfaction as $0 / 268$ standard deviation decreases. In this equation, because they have been standardized coefficients, as well as the effect of each variable on the dependent variable can be realized. Here is observed that the variables compared to other variables feel the satisfaction of needs greater share of family life satisfaction is explained Tables 4 and 5 shows the results.

Table regression multivariate analysis of variance Hypothesis's research

\begin{tabular}{|c|c|c|c|c|c|c|c|}
\hline Model & $\begin{array}{l}\text { Freedom } \\
\text { lies }\end{array}$ & $\begin{array}{l}\text { Sum of } \\
\text { squares }\end{array}$ & $\begin{array}{c}\text { Mean } \\
\text { Square }\end{array}$ & $\begin{array}{c}\text { The } \\
\underset{\text { quantity }}{\mathbf{f}}\end{array}$ & $\begin{array}{c}\text { The } \\
\text { significant } \\
\text { level of } f\end{array}$ & $\begin{array}{c}\text { multiple } \\
\text { regression }\end{array}$ & $\mathbf{R 2}$ \\
\hline Regression & 8 & $35594 / 069$ & $4449 / 259$ & \multirow{3}{*}{$69 / 688$} & \multirow{3}{*}{$0 / 000$} & \multirow{3}{*}{$0 / 76$} & \multirow{3}{*}{$0 / 58$} \\
\hline left over & 391 & $24963 / 545$ & $63 / 845$ & & & & \\
\hline Total & 399 & $60557 / 614$ & - & & & & \\
\hline
\end{tabular}

Table: Results of multivariate regression research Frzyh $\neg$ Hay

\begin{tabular}{|c|c|c|c|c|c|}
\hline $\begin{array}{c}\text { Indices } \\
\text { Variables }\end{array}$ & B & $\begin{array}{c}\text { The } \\
\text { standard } \\
\text { error }\end{array}$ & Beta & $\begin{array}{c}\text { The } \\
\text { amount } \\
\text { of t }\end{array}$ & $\begin{array}{c}\text { Significance } \\
\text { level }\end{array}$ \\
\hline Constant & $90 / 926$ & & & & \\
\hline Feel the satisfaction of needs & $0 / 257$ & $0 / 060$ & $0 / 271$ & $4 / 311$ & $0 / 000$ \\
\hline Making unilateral power driven father & $-0 / 389$ & $0 / 095$ & $-0 / 248$ & $-4 / 117$ & $0 / 000$ \\
\hline Making unilateral power-driven mother & $-0 / 849$ & $0 / 141$ & $-0 / 268$ & $-6 / 002$ & $0 / 000$ \\
\hline
\end{tabular}

\section{Conclusion}

In this study, four hypotheses using Maslow's theories, Ingelhart, we develop and test correlation Homans took the test. In the meantime, three hypotheses were confirmed. According to the first hypothesis, satisfaction with family life satisfaction has a significant relationship, this hypothesis was tested in a real environment and was confirmed by the findings of Elite Zardmooy (2011), in relation to satisfy needs and life satisfaction family is similar. According to the second hypothesis, the sense of justice has significant relationships with life satisfaction. This hypothesis was tested in a real environment and could not be verified. The significance of the relationship between justice and family life satisfaction, the findings of this study's findings Hezarjaribi (2010) is no similarity. The third hypothesis, a sense of freedom and satisfaction with family life meaningful relationship. This hypothesis was tested in a real environment and was confirmed by the findings of Elite Zardmooy (2011), the connection test is similar to the feeling of freedom with family life satisfaction. The fourth hypothesis, family structure has a significant correlation with life satisfaction. This hypothesis was tested in a real environment and its components (power structure driven father, mother driven, proportional and symmetrical all-round symmetrical) was confirmed. Satisfaction element, a basic element of discipline, unity in society is. It should be noted that there is continuing dissatisfaction in people's lives for each Social system is problematic and the family as a social institution and as a mirror of society in itself and a reflection of social disorder. In the private sector, lack of consent or a sharp decline of family life means that the family in the outcome of pregnancy failure, deviations And social damage will be significant and worrying that may occur with any 
small event the negative potential from potential to actual and potential not find. Since the relationship between the variables satisfy the needs of family life satisfaction in the study were statistically significant Should parents all its efforts to satisfy their needs, especially in the higher levels of Maslow's needs do and because adolescents who have a family power structure was symmetrical all-round satisfaction had higher Parents should be allowed to participate in family matters and to give them advice And their role in family life and society as desirable to give children freedom to act as a guide in this regard. In order to do further research in the field of family life satisfaction proposal that can be presented, This is the issue with sample sizes and among other population groups (rural-urban) were investigated.

Researchers also recommended that the scope of family life satisfaction on the question of family life satisfaction through qualitative research _ particularly in-depth interviews with people in order to understand the factors affecting the focus. And periodic surveys of family life satisfaction on a national level non-governmental sector be supported by the scientific community And the universities to conduct student surveys and surveys of graduates is about supporting family life satisfaction.

\section{References:}

1) Azimi, M. (1382). The relationship between religiosity and life satisfaction among students, Mashhad, Khorasan Investigation Department of Education.

2) Gurr, Tedd Robert (1970) . "Why Men Rebel, Princeton, N.J: Princeton University Press.

3) Hezarjaribi, J. and Austin volcano, P. (1388). Factors affecting social vitality, Institute for Humanities and Cultural Studies, the twentieth year, Serial (33 ((1)

4) Hezarjaribi, Jafar and Safari Shali, R. (1388) .brrsy finally signifying the place feel safe in their life satisfaction, Journal - of social regulation, the first year, the third number

5) Hezarjaribi, Jafar and Safari Shali, R. (1388) Social .refah and the factors affecting it, the Research and Urban Planning, Issue $\mathrm{V}$

6) Hosseini, Seyed Reza (1383). Crime statistics in 1380-1376, the first national conference of social pathologies in Iran Papers, Volume I, published aware, Tehran

7) Inglehart, Ronald and Welzel (1378) and the transformation of economic .amniyt value, translation Shahnaz Shafi Khani. A study, numbers 14 and 15

8) Karolyn ,henroy. (1994). " family system charactoriestics : parental behaviors and adolescents family life satisfaction , jornal of family relation;oct

9) Madandar, L. (1388) .baresy factors affecting life satisfaction, Master Thesis Sociology, University of Al-Zahra

10) Maslow, Abraham H. (1367). Motivation and Personality, translator Ahmad Radwan, Mashhad, Shrine Seal

11) Mohsen Manouchehr Salehi, P. (1382) Social .satisfaction in Iran, the publication notes

12) Mohsen, M. (1379) .baresy knowledge, attitudes and sociocultural behaviors in Iran, First Edition, Tehran, publish Secretariat of the General Council Country

13) Mokhtari, Marzieh, theoretical, J. (1389) Quality of Life sociologists, sociologists Publishing, Printing, Tehran
14) Sarookhani, B and Amir Panahi, M. (1385). Making power in the family and community involvement, research Women, Volume 4, Issue 3

15) Sarookhani, B. (1392). Introduction to the sociology of the family, Tehran, Soroush Publications

16) Share pour, A. (1387) .baresy votes Simmel, Institute of Comprehensive Human Sciences

17) Barzegar, L. (1386) .sanjesh the happiness of citizens, Master Thesis Sociology, University of Al-Zahra

18) Disch ,William(2000).student functioning ,concern ,and social personal well being.social indicator Research 5

19) Golchin, M and Zardmooy ordkeloo, Shapur (1389). Tehrani adolescents family life satisfaction in the fulfillment of order in the family. Journal of Social Sciences Faculty of Literature and Humanities University of Mashhad

20) Kapteyn ,Arie \&Smith , james(2009). life satisfaction. Research in University the Netherlakd.

21) Tavasoly, G. (1389) .Teories of Sociology, published XVI, Tehran

22) Valdman, Richard (1380). Social exchange theory, translated by Mohammad Saeed Zokaee, Institute of Comprehensive Human Sciences 